\title{
ФОРМИРОВАНИЕ МЕСТОРОЖДЕНИЙ ЛЕГКОПЛАВКИХ ГЛИН В ПОЗД- НЕМ ПЛЕЙСТОЦЕНЕ И ГОЛОЦЕНЕ В КАРЕЛО-КОЛЬСКОМ РЕГИОНЕ
}

\author{
В. Я. Евзеров \\ Геологический институт Кольского научного центра РАН, г. Апатиты
}

Поступила в редакцию 18 марта 2019 г.

\begin{abstract}
Аннотация: месторождения глин Карело-Кольского региона образовались, преимущественно, вследствие дифференцииации обломочного материала, переносимого ледником. Этот материал содержал очень небольшое количество мелких частиц. Его дифференцииация осуществлялась тальми ледниковыми водами и мутьевыми потоками, зарождавщимися на передовых склонах флювиоглячиальных дельт в пресноводных и морских водоёмах. В Кольском регионе обнаружено 25 месторождений и проявлений глин. 19 из них - это ледниково-морские глины, сформировавщиеся при рассекающей дегляциаџии в морских заливах. В Карелии установлено 71 месторождение и проявление глин. Подавляющее больиинство из них представлено озерно-ледниковыми глинами, которые образовывались как при рассекающей, так и при ареальной деглячиации. Сконцентрированы они, соответственно указанным типам дегляцииции, в окрестностях Онежского озера и Ладожской котловины. При фронтальной дегляциаџии месторождения глин могут сформироваться только в случае более или менее длительного стаџионарного положения края ледника при наличии приледниковых водоёмов. В Карелии также встречаются очень редко месторождения ледниковых и несколько чаще морских и озерных глин.

Ключевые слова: Карело-Кольский регион, поздний плейстоцен-голоцен, дегляииация, месторождения легкоплавких глин
\end{abstract}

\section{FORMATION OF EASILY FUSIBLE CLAY DEPOSITS IN LATE PLEISTOCENE AND HOLOCENE IN KARELIAN-KOLA REGION}

\author{
V. Ya. Yevzerov \\ Geological Institute - Subdivision of the Federal Research Centre \\ "Kola Science Centre of the Russian Academy of Sciences», Apatity
}

Received 18 March 2019

\begin{abstract}
The clay deposits of the Karelian-Kola region were mainly formed due to the differentiation of detrital material transported by a glacier. This material contained a very small amount of fine particles. Its differentiation was carried out by glacial melt waters and turbid streams that originated on the advanced slopes of the fluvioglacial deltas in freshwater and marine water bodies. In the Kola region, 25 deposits and clay occurrences were found. Nineteen of them are glacial-marine formations formed during dissecting deglaciation in the gulfs. In Karelia, 71 deposits and clay occurrences have been established. The overwhelming majority of them are represented by lake-glacial clays, which were formed during both dissecting and areal deglaciation. They are concentrated, in accordance with the indicated types of deglaciation, in the environs of Lake Onega and Ladoga Basin. During frontal deglaciation, clay deposits can form only in the case of a more or less long stationary position of the glacier margin in the presence of periglacial water bodies. In Karelia, glacier clay deposits occur very seldom, marine and lake clays are found slightly more often.
\end{abstract}

Key words: Karelian-Kola region, Late Pleistocene-Holocene, deglaciation, deposits of easily fusible clays

(c) Yevzerov V. Ya., 2019

Контент доступен под лицензией Creative Commons Attribution 4.0 License.

The content is available under Creative Commons Attribution 4.0 License. 


\section{Введение}

Месторождения легкоплавких глин широко распространены в Карело-Кольском регионе. Они сформировались в позднем плейстоцене - голоцене, в основном, при деградации поздневалдайского оледенения. Более полная информация имеется по глинам Кольского региона. Она включает сведения о запасах и генезисе всех месторождений. Что касается Карелии, то в капитальной сводке по месторождениям республики [1] приведены только запасы месторождений и проявлений, но не сообщается о генезисе каждого из них.

В данной статье детализированы и расширены сведения о формировании и размещении месторождений глин, которые в обобщенном виде опубликованы в предыдущей статье автора [2].

Для понимания и объяснения механизма образования месторождений глин весьма существенное значение имеют данные, дающие возможно более полное представление о составе обломочного материала, имевшегося в теле покровного ледника, при дифференциации которого возникли глины, и о самих процессах дифференциации.

\section{Поступление обломочного материала в ледниковый покров и формирование покровной морены}

В период максимального распространения ледникового покрова обломочный материал поступал в него снизу, в основном, вследствие примерзания к подошве ледника водонасыщенных осадочных пород ложа и посредством нагнетания рыхлых пород ложа в трещины во льду. Частично обломочный материал попадал в тело ледника в виде небольших отторженцев осадочных пород, а также на его поверхность при наличии нунатаков - горных вершин, возвышающихся над ледниковым покровом. Близость вещественного состава нижней части разреза основной морены и подстилающих пород, а также зависимость от характера последних гранулярного состава мелкозема морены, установленные при исследованиях в пределах Кольского региона [3], свидетельствуют о том, что нижние слои льда сравнительно быстро насыщались обломками, теряли пластичность и отслаивались от продолжающего перемещаться ледникового покрова. Господствующим было пластическое течение льда. Уплотнение ставшего неподвижным мореносодержащего льда, сопровождаемое таянием-замерзанием, приводило к его обезвоживанию и замещению мореной. Отслаивание происходило неоднократно и, очевидно, именно этот процесс являлся ведущим в накоплении основной морены. Обломочный материал, выведенный, в основном, по сколам и надвигам в тело ледникового покрова, смешивался с обломками, которые поступали в него с крупных возвышенностей коренного ложа. Этот разнородный материал совместно с обломками, поставляемыми нунатаками, большей частью перемещался на значительные расстояния и отлагался в фазу деградации оледенения, образуя верхний горизонт моренного пласта, в котором преобладают эрратические обломки, и гранулярный состав мелкозема которого утрачивает зависимость от состава подстилающих пород. В формировании верхней части пласта морены в отдельных участках существенную роль играли талые ледниковые воды. В этом случае возникала абляционная морена, которая в конкретных разрезах зачастую может быть выделена лишь при наличии подстилающей ее основной морены. Очевидно, аналогичные процессы имели место и при формировании морены на территории Карелии.

Данные по гранулярному составу морены КарелоКольского региона приведены в обстоятельной работе А. А. Каган и М. А. Солодухина [4]. В естественной смеси (морене) на долю частиц размером $<0,002$ мм (собственно глинистых) приходится не более 2-5\%, а частиц соседней несколько более крупной фракции (0,05-0,002 мм) от 7 до $20 \%$. При столь небольших количествах частиц указанных размеров в естественных смесях возникает необходимость расшифровки процесса дифференциации обломочного материала при накоплении глинистых отложений.

\section{Формирование глинистых отложений при} дифференциации обломочного материала

В ходе деградации ледника, начиная с момента четкого обособления лопастей и языков, обусловленного влиянием рельефа подстилающих пород и внутренней неоднородностью покрова (примерно с межстадиально-стадиального цикла бёллингдревний дриас) в пределах его распространения начинают формироваться водно-ледниковые магистрали. Они ориентировались преимущественно по направлению движения льда в каждой области и закладывались, очевидно, по системам трещин. Основная масса талых ледниковых вод через лабиринт трещин во льду устремлялась в депрессии. Сток вод c переносимым ими обломочным материалом направлялся к водоёмам как морским, так и пресноводным. При впадении в водоемы флювиогляциальные потоки образовывали дельты. У дистального края дельт накапливались глинистые толщи, механизм формирования которых из мутьевых потоков подробно рассмотрен в работе автора [5]. В этих толщах выделяются проксимальные и дистальные части различной протяженности. Последние, собственно, и представляют собой месторождения глин. В пресноводных водоёмах они расположены на расстоянии нескольких километров от передового склона дельты. Это типичные ленточные глины, подсчет слойков которых позволяет определить продолжительность существования приледникового водоёма, а в сочетании с палеомагнитными исследованиями, как это сделано в Усть-Пялкской залежи глин Кольского региона, и оценить время их формирования [6]. В солоноватоводных и морских водоёмах под воздействием электролитов происходит коагуляция глинистых частиц, и они оседают на расстоянии пер- 
вых сотен метров от передового склона дельт. Достаточно подробная характеристика отложений упомянутых водоёмов имеется во многих работах [5-8 и др.].

\section{Месторождения глин Карело-Кольского региона}

Месторождения глин принадлежат к обширной группе общераспространенных полезных ископаемых. При разделении месторождений по размерам запасов глин в данной статье мы сочли целесообразным взять за основу подразделения не всей упомянутой выше группы полезных ископаемых, а конкретные данные по месторождениям глин. Они приведенны в таблице 2.3.3.6 [1] фундаментальной сводки материалов по минерально-сырьевой базе Республики Карелия, распространив их и на Кольскую часть рассматриваемого региона.

Месторождения и проявления глин региона, числящиеся на балансе, по размерам запасов разделены на три группы: крупные, средние и мелкие с запасами, соответственно, свыше 10 млн. куб. м, от 10 до 2.5 млн. куб. м и менее 2.5 млн. куб. м. согласно класси- фикации, взятой в [1]; выделены также и забалансовые месторождения. В дальнейшем изложении в скобках на рисунке указаны номера месторождений и проявлений по данным таблицы 2.3.3.6 из работы [1].

В Кольском регионе обнаружено 25 месторождений и проявлений глин. Из них с запасами по категориям $\mathrm{A}+\mathrm{B}+\mathrm{C}_{1} 3$ являются средними и 4 мелкими, а с запасами по категориям $\mathrm{C}_{2}+$ прогнозные -4 крупными, 7 средними, 6 мелкими и 1 забалансовым. Из 25 месторождений 19 представлено ледниково-морскими образованиями, сформировавшимися в морских заливах при рассекающей дегляциации, 2 - озерноледниковыми, образовавшимися при ареальной дегляциации, и 4 - послеледниковыми морскими глинами. Подробные сведения о месторождениях региона приведены в статье автора [5].

В Карелии установлено 71 месторождение и проявление глин (табл. 1). Из них по категории запасов $\mathrm{A}+\mathrm{B}+\mathrm{C}_{1} 3$ являются средними и 31 мелкими, а по категории $\mathrm{C}_{2}+$ прогнозные 6 - крупными, 10 - средними и 12 - мелкими. 9 скоплений глин забалансовые.

Таблица 1

Сведения о масштабах запасов сырья в месторождениях Карелии

\begin{tabular}{|c|c|}
\hline \multicolumn{2}{|c|}{ Месторождения с запасами по категориям } \\
\hline $\mathrm{A}+\mathrm{B}+\mathrm{C}_{1}$ & Номера месторождений \\
\hline Крупные (свыше 10 млн. м³) & \\
\hline Средние $\left(2,5-10\right.$ млн. м $\left.{ }^{3}\right)$ & $22,50,51$ \\
\hline Мелкие ( менее 2,5 млн. м ${ }^{3}$ ) & $\begin{array}{l}1,3,8,13,17,18,19,23,24,25,26,29,29.1,30,31,32, \\
37,38,42,4344,52,53,54,57,62,63,67,68,69,71\end{array}$ \\
\hline \multicolumn{2}{|l|}{$\mathrm{C}_{2}+$ прогнозные } \\
\hline Крупные (свыше 10 млн. м³) & $28,39,40,55,58,66$ \\
\hline Средние $(2,5-10$ млн. м³) & $4,9,10,33,41,46,47,59,61,64$ \\
\hline Мелкие ( менее 2,5 млн. м³) & $2,5,7,16,21,34,35,36,48,56,60,70$ \\
\hline Забалансовые & $6,11,12,14,15,20,27,45,65$ \\
\hline
\end{tabular}

Примечание: номера месторождений и проявлений глин аналогичны таковым в таблице 2.3.3.6 [1].

Расположение месторождений и проявлений глин показано на приведенном ниже рис. 1.

Месторождения и проявления глин:1 - a - крупные (запасы свыше 10 млн. куб. м); б - средние (запасы 2,5-10 млн куб. м); в - мелкие (запасы менее 2,5 млн куб. м). На схеме красным показаны месторождения с запасами по категориям $\mathrm{A}+\mathrm{B}+\mathrm{C}_{1}$, синим - по категориям $\mathrm{C}_{2}$ и $\mathrm{P}_{1}+\mathrm{P}_{2}$; белым - забалансовые. Номера месторождений и проявлений на схеме отвечают таковым в таблице 2.3.3.6 [1]. Краевые образования: 2 аллерёда, 3 - позднего дриаса; 4 - площадь распространения позднеплейстоцен-голоценовой морской трансгрессии (а) и граница приледниковых водоёмов (б). Приняты сокращения названий ледниковых стадий: $\mathrm{V}-\mathrm{Kr}$ - вепсовско-крестецкая, $\mathrm{Lu}$ - лужская, $\mathrm{N}$ невская, $\mathrm{Al}$ - аллерёдская и $\mathrm{Dr}_{3}$ - позднедриасовая.

Фациально месторождения и проявления глин Карелии более разнообразны, чем аналогичные образования Кольского региона. В Карелии, помимо озерно-ледниковых, ледниково-морских и морских глин, обнаружены проявления ледниковых и озерных глин. Что касается генезиса глинистых образо- ваний в каждом конкретном пункте изучения, то, как отмечалось во введении, такие данные в полном объеме отсутствуют, значительную часть из них удалось обнаружить в ряде работ карельских геологов $[9,11,12$ и др.].

На этапе наибольшего развития последнего ледникового покрова в вепсовско-крестецкую и луцкую стадии по И. Н. Демидову [12] морены формировались, главным образом, за счет ассимиляции и переотложения более древних четвертичных, а на крайнем юге района и палеозойских образований преимущественно глинистого состава. Морены здесь содержат до 50-70 \% частиц размером $<0,01$ мм. В них установлено и небольшое количество мелких месторождений глин: Другая Река (68), Рыборецкое (69), и др.

Подавляющее количество месторождений легкоплавких глин в Карелии являются озерно-ледниковыми. Они расположены, главным образом, в районах Онежской и Ладожской впадин. Эти месторождения, как показал И. Н. Демидов [9], формировались в Онежской депрессии при рассекающей дегляциации, 


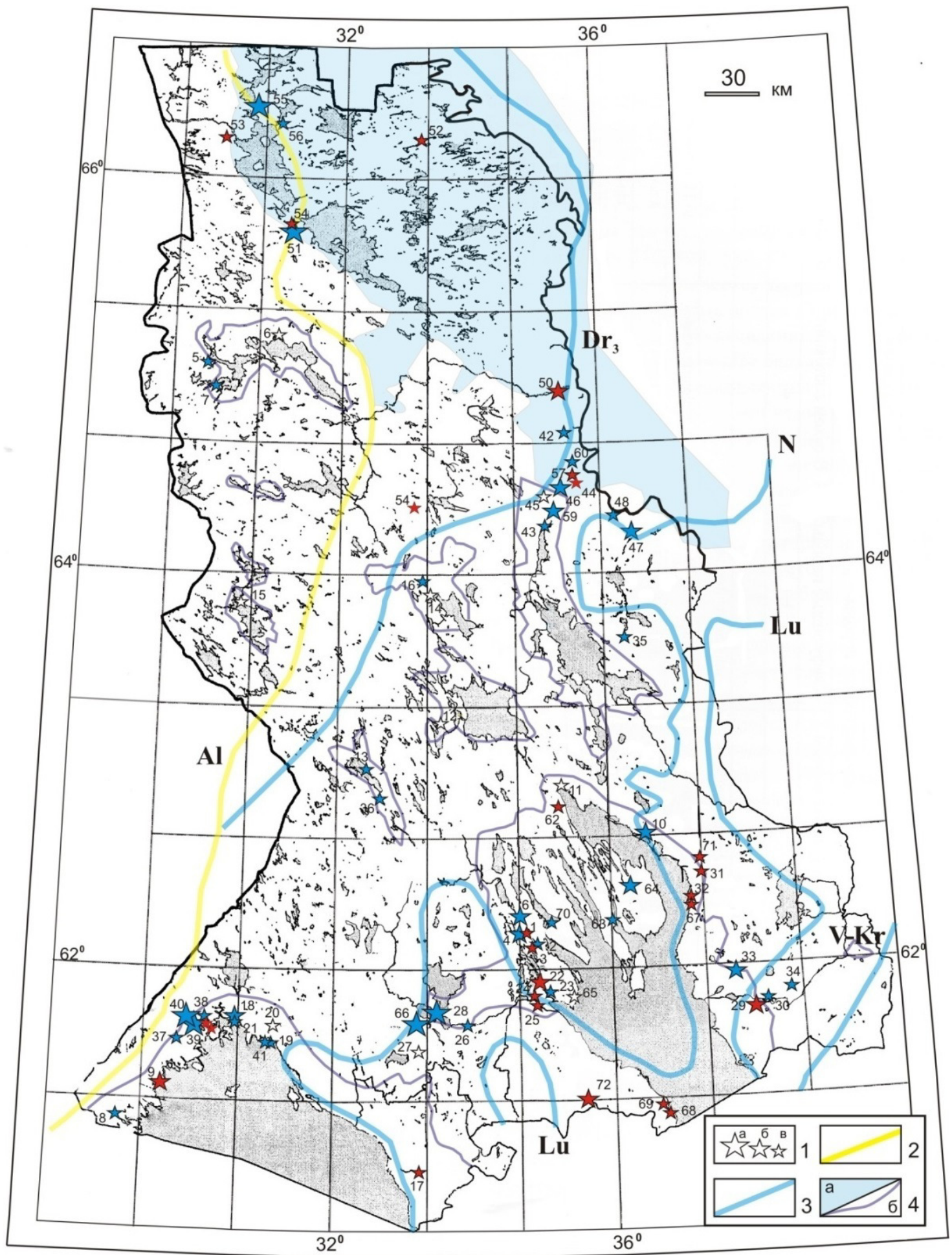

Puc. 1. Схема распространения краевых ледниковых образований, приледниковых водоёмов и месторождений легкоплавких глин Карелии по $[1,9]$ с дополнением по [10].

а в Ладожской, по данным автора [2], - при дегляциации ареальной, когда в аллерёде край активного льда длительное время находился в более или менее стационарном положении. Рассекающая дегляциация в Карелии имела место и в окрестностях Кандалакшского залива вследствие развития позднеплейстоценголоценовой морской трансгрессии. Однако на этой площади (рис. 1.) достоверно установлены только месторождения морских глин. Некоторые из них, например, Шуерецкое (42) Летнереченское (43), Кемское (50), Ново-Софпорог (51), Софпорог (54) и Кумское (55) вполне могли сформироваться вследствие переотложения на мелководье ледниковоморских отложений. 
Проявления глин озерного генезиса встречаются довольно часто. Они сконцентрированы в районах некогда существовавших пресноводных приледниковых водоёмов, главным образом, в пределах крупного бассейна в северной части Онежской впадины: Пергубское (62), Великогубское (63), Падмозерское (64) и др., реже вблизи морского побережья Кандалакшского залива: Сорокское (57), Лейп-ручей (60) и др. Вероятно, в этих водоёмах накапливались отложения, обогащенные глинистым материалом. После исчезновения водоёмов в озерных котловинах глинистый материал аккумулировался вследствие волновой переработки береговых образований.

В предыдущей работе, посвященной месторождениям строительных материалов Карело-Кольского региона, автором [2] показано, что на большей части территории Карелии проявилась ареальная дегляциация. Активное отступление фронта ледника происходило на небольшой по площади территории, заключенной между луцкими и невскими краевыми образованиями. В её пределах обнаружено небольшое количество месторождений. Однако обращает на себя внимание наличие нескольких крупных и средних по масштабам запасов проявлений вблизи краевых образований невской стадии: Ревзунского (28), Сумпосадского (47) и Ламбисельга (66). Вероятно, они сформировались в приледниковых водоёмах в условиях длительного сохранения активности ледниковых лопастей при более или менее стабильном положении края ледника, как это, обычно, имеет место при ареальной дегляциации.

\section{Заключение}

На территории Мурманской области и Карелии широко распространены месторождения и проявления легкоплавких глин. 25 скоплений глин выявлено в Кольском регионе. Абсолютное большинство из них представлено ледниково-морскими образованиями, сформировавшимися в морских заливах Баренцева моря при рассекающей дегляциации региона.

В Карелии обнаружено значительно больше месторождений и проявлений аналогичного сырья - 71. Доминируют здесь скопления озерно-ледниковых глин, которые в районе Онежской котловины образовались при рассекающей дегляциации, а в окрестностях Ладожской депрессии - при дегляциации ареальной. Месторождения морского генезиса Карелии, частично, возникли, вероятно, в результате переотложения волнами на мелководье глин ледниково-морского происхождения. Для формирования месторождений глин наименее благоприятна фронтальная дегляциация. При активном отступлении ледникового покрова условия

Геологический институт ФГБУН Федерального исследовательского центра «Кольский научный центр Российской академии наук» (ГИ КНЦ РАН), г. Апатить

Евзеров Владимир Яковлевич, доктор геологоминералогических наук

E-mail: yevzerov@geoksc.apatity.ru; Teл.: +7 (81555) 62793 для накопления глин создавались, вероятно, только в приледниковых водоёмах в обстановке более или менее длительного стационарного положения края ледника подобно тому, как это обычно имеет место при ареальной дегляциации. Проявления глин озерного генезиса сконцентрированы в районах некогда существовавших пресноводных приледниковых водоёмов. Очень редки месторождения ледникового генезиса, встречающиеся только в южной части региона.

Работа выполнена в рамках темы НИР ГИ КНЦ PAH № 0226-2019-0053.

\section{ЛИТЕРАТУРА}

1. Минерально-сырьевая база республики Карелия / Петрозаводск: «Карелия». Книга 2, 2006. - 355 с.

2. Евзеров, В.Я. Типы дегляциации и распространение месторождений строительных материалов в позднеплейстоцен-голоценовых отложения Карело-Кольского региона / В. Я. Евзеров // Вестник Воронеж. гос. ун-та. Сер.: Геология. -2019 . - № 1. - С. 58-63.

3. Евзеров, В. Я. Литология морены поздневалдайского оледенения западной части Кольского полуострова / В.Я. Евзеров // Вестник МГТУ, Труды Мурманского государственного университета. - Т. 20. - №1/1. - 2017. - С. 48-59.

4. Каган, А. А. Моренные отложения северо-запада СССР. $/$ А. А. Каган, М. А. Солодухин. - М.: Недра. 1971. - 137 с.

5. Евзеров, В. Я. Ресурсы, размещение и формирование месторождений кирпичных глин Мурманской области, Северо-запад России / В. Я. Евзеров // Вестник Воронеж. гос. унта. Сер.: Геология. - 2005. - № 2. - С. 120-141.

6. Бахмутов, В. Г. Литология и палеомагнетизм поздневалдайских отложений Усть-Пялкского приледникового озера / В. Г. Бахмутов, В. Я. Евзеров, В. В. Колька // Геофизический журнал. - 1992. - Т.14. - № 6. - С. 62-74.

7. Лаврова, М. А. Четвертичная геология Кольского полуострова. / М. А. Лаврова. - М.-Л.: изд. АН СССР, 1960. $233 \mathrm{c}$.

8. Колька, В. В. Геология и условия формирования позднеледниковых глин Кольского полуострова : дис. ... канд. геол.-мин. наук: 04.00.01: защищена 26.04.96 / Василий Васильевич Колька. - Москва, 1996. - 213 с.

9. Демидов, И. Н. Деградация поздневалдайского оледенения в бассейне Онежского озера / И. Н. Демидов // Геология и полезные ископаемые Карелии. - Вып.8. - Петрозаводск: Карельский научный центр РАН, 2005. - С. 134-142.

10. Евзеров, В. Я. Геология четвертичных отложений Кольского региона. / В. Я. Евзеров. - Мурманск: Изд. МГТУ, 2016. $-210 \mathrm{c}$.

11. Митрофанова, 3. Т. Глины Карелии. / 3. Т. Митрофанова, Г. П. Филинцев. - Гос. Издательство Карельской АССР. Петрозаводск, 1956.- 160 с.

12. Демидов, И.Н. Этапы формирования и особенности локализации полезных ископаемых Карелии в четвертичном периоде / И. Н. Демидов // Рос. АН. Карельский научный центр. Институт геологии. - Вып. 1. - Петрозаводск, 1998. C $137-143$.

Geological Institute - Subdivision of the Federal Research Centre «Kola Science Centre of the Russian Academy of Sciences» (GI FRC KSC RAS), Apatity

Yevzerov V. Ya., Doctor of Geological and Mineralogical Sciences

E-mail: yevzerov@geoksc.apatity.ru; Tel.: +7 (81555) 62793 